\title{
Sow Behavior Expression: Adoptions Effect
}

\author{
Paula Arroyo ${ }^{1}$, Santiago Corva ${ }^{2}$, Hector Ricardo Ferrari ${ }^{3}$, Alicia \\ Graciela Antonini ${ }^{1}$
}

\author{
${ }^{1}$ Veterinary Genetics Institute (IGEVET-UNLP-CONICET) \\ ${ }^{2}$ Veterinary Sciences Faculty, UNLP \\ ${ }^{3}$ Natural Sciences and museum Faculty, UNLP
}

\begin{abstract}
Crossed adoptions based on female potential are recommended in commercial production. This are made in the first 24 hours postpartum because it is at this moment that the imprinting occurs, it is the process by which certain stimuli are associated to produce different behaviors. In order to decrease or eliminate the recognition of the strange piglet, prior to introducing it into the new litter, different strategies are carried out. Early experiences may have long-term effects on future behavior. These experiences are influenced by mother-litter interaction. The aim of this work was to determine the possible association between adoptions and sows behavioral modifications. Females that donated piglets spent more time "walking" than those who did not donate piglets $(\mathrm{p}<0.05)$. And there is a possible relation between farrowing and the condition of being raised by an adoptive mother $(\mathrm{p}<0.05)$.
\end{abstract}

Keywords: Sow Behavior, Nursing, Swine Production, Adoptions

\begin{abstract}
Introduction
A common practice in production systems is crossed adoptions, in order to standardize the litters in piglet number and size. Crossed adoptions based on female potential are recommended in commercial production [8]. That is why this practice analysis has been studied and its impact on female behavior. Adoptions are made in the first 24 hours postpartum because it is at this moment that the imprinting occurs, in which the knowledge of one by the other will be made, in both directions and will be permanent. It is the process by which certain stimuli are associated to produce different behaviors [13]
\end{abstract}

In order to decrease or eliminate the recognition of the strange piglet, prior to introducing it into the new litter, different strategies are carried out, like wrap the piglet in the adoptive mother placenta, put it in contact and rub it with the female's piglets, mask the piglet smell with some substance scattered near the sow's nostrils, etc. In pig the smell is one of the most outstanding senses, and this has a great influence on behavior [11]. [14] studied the behavioral differences in females that raised piglets born from other sows, and found that females with adopted piglets decrease the time between suckling and increase non-nutritious nursing, thus decreasing the investment of resources in raising piglets that are not their own.

Early experiences may have long-term effects on future behavior. These experiences are influenced by mother-litter interaction through various mechanisms
[4]. A female behavior can be influenced by the quality or quantity of maternal care received [3]. Gilts learn how to behave by imitating their mothers [5].

The aim of this work was to determine the possible association between adoptions and sows behavioral modifications.

\section{Materials and methods}

Data were obtained under production conditions and the influence of the observer was standardized by collecting it by a single person [9] [5].

Observations were made on the behavior of lactating sows of two breeds, Landrance and Yorkshire. Sows belong to a commercial farm located in the northern area of Buenos Aires province, Argentina. They were housed in $60 \mathrm{~cm} \times 210 \mathrm{~cm}$ cages. Females were housed into the maternity sheds one week before the birthand they remained there until weaning, at 28 days of lactation. They were fed 4 times a day and had water "ad libitum".

In the ethogram construction stage, 3 daily observation sessions were made (7:30-8:30, 10:3011:30 y 14:00-15:00) [10] from Monday to Saturday. Observation technique was "ad libitum", observations without structure of any kind [1]. The cut point criterion for the ethogram used was the asymptote method, curve in which new patterns are confronted by observation session, and total accumulated 
patterns. When thus remain constant, the preparation of the behavior list is completed [12]. The cut occurred after 4 months of observation.

During the measuring frequency and time of behavioral patterns stage,observation sessions were recorded in continuous filming of 5 minutes per day per female. Observation method was Focal Animal, individual observations per animal [1]. All observations were made with no workers in maternity [5].

Adoptions were made during the first 24 hours postpartum. A detailed record of theoffspring litter changes was made.They were temporarily marked in the tail until seven days of age, when they were identified and registered with the individual identification and corresponding to their litter birth

For data statistical analysis, a negative binomial regression was used [6] for each behavior observation, depending on time, regarding whether she had donated piglets to another female and if it had received offspring from another sow. (Stata II IC (JICA Provetsur)). And $\chi^{2}$ (Ji-square) analysis to study the possible relation between the gilts breeding condition, adopted or not, and its reproductive behavior.
$\operatorname{Ln}(\lambda)=B_{i}+U_{j}+P_{k}+R_{l}+D_{m}+R_{n}$
B: Nursing week
U: Cage location
P: Parity
R: Breed
D: Donated piglets
Re:Received piglets

\section{$\underline{\text { Results }}$}

Females that donated piglets spent more time "walking" than those who did not donate piglets. $(\mathrm{p}<0.05)$

Females that received piglets spent more time "lateral cast" than those who did not receive piglets. $(\mathrm{p}<0.05)$

Differences in the gilts reproductive behavior

Table $\mathrm{n}^{\circ}$ : Future breeders following

\begin{tabular}{|l|l|l|l|}
\hline & Selected & Heat repetition & Farrow \\
\hline Adopted/no adopted & $\mathrm{p}<0,05$ & $\mathrm{p}>0,05$ & $\mathrm{p}<0,05$ \\
\hline
\end{tabular}

Therefore, there is apossible relation between the breeding condition (adopted/not adopted) and being selected or not for replacement $(\mathrm{p}<0.05)$.

In this way it is evident that there is a possible relation between farrowing and the condition of being raised by an adoptive mother $(\mathrm{p}<0.05)$.

\section{Discussion}

Some authors found that females receiving other piglets had longer intervals between breastfeeding and increased non-nutritious breastfeeding. According to [2], females with adopted piglets have higher frequencies of non-nutritious suckling and decrease the time of suckling [14]. According to [10] sows modified their behavior towards strange offspring and their piglets handling. In this work, sowsbehavior was modified, both of those who received or donated piglets, and of the piglets that were donated.

Sows that received piglets spent more time "lateral cast",and those who donated piglets spent more time "walking", these behavioral differences show that beyond controlling and masking all aspects of the recognition between the female and her offspring, these manipulations are perceived by both categories (mother and offspring) and their behavior are modify accordingly.

In the case of the donated and raised by other sows piglets the adoption consequences were found in the changes of their reproductive behavior, since it is a possible explanation to have not been inseminated, once they were selected to move from the rearing stage to the future breeders housing and management, (in this productive stage females are selected by heat behavior). And according to the results there was an association between being adopted and the selection or service during this stage, and give birth after being inseminated. [5] Mention that the offspring future behavior can be influenced by the postnatal environment, and that a female behavior can be influenced by the quality or quantity of maternal care received. [3] Specifies that there is a link between early experiences and behavior, and concludes that changes in behavior are observed in separate offspring of their mothers. These results agree with thus proposed by these authors.

From observing behavioral differences between biological sisters raised by their own mothers and those that were separated at birth from their mother and littermates we can conclude the high impact on the expression of heat behavior and the pregnancy of the offspring. This allows us to assume that gilts that will be considerate for the reproductive replacement should be raised by their owns mothers. 


\section{Conflicts of interest}

All authors declared there is no conflict of interest, including financial, personal or other relationships with other people or organizations that could inappropriately influence this paper.

\section{Bibliography}

1. Altmann J. Observational study of behavior: sampling methods. Behavior 1974; vol 49, parts 3-4, pp 227-267

2. Algers B. Nursing in pigs: communicating needs and distributing resources. J Anim Sci. 1993;71(10):2826-31.

3. Champagne FA. Maternal imprints and the origins of variation. HormBehav [Internet]. 2011;60(1):4-11. Available from: http://dx.doi.org/10.1016/j.yhbeh.2011.02.016

4. Champagne FA. Epigenetic mechanisms and the transgenerational effects of maternal care. Front Neuroendocrinol. 2008;29(3):386-97.

5. Chidgey KL, Morel PCH, Stafford KJ, Barugh IW. The performance and behaviour of gilts and their piglets is influenced by whether they were born and reared in farrowing crates or farrowing pens. LivestSci. 2016;193(December 2015):51-7.

6. Dohoo, I. R., Martin, W., \&Stryhn, H. Veterinary epidemiologic research (No. V413 DOHv). Charlottetown, Canada: AVC Incorporated.(2003).

7. Francis D. Nongenomic Transmission Across Generations of Maternal Behavior and Stress Responses in the Rat. Science
(80- ) [Internet]. 1999;286(5442):1155-8. Available from: http://www.sciencemag.org/cgi/doi/10.1126/science.286.544 2.1155

8. García-Munguía CA, Ruíz-Flores A, López-Ordaz R, GarcíaMunguía AM, Ibarra-Juárez LA. Comportamiento productivo y reproductivo al parto y al destete en cerdas de siete líneas genéticas. RevMex Ciencias Pecu. 2014;5(2):201-11.

9. Hellbrugger B. Genetic aspect of piglet losses and the maternal behaviour of sows. Dr Thesis [Internet]. 2007; Available from: http://www.tierzucht.unikiel.de/dissertationen/diss_hellbrueg ge.pdf

10. Hernández A. Conducta de la cerda doméstica y su camada behavior of domesticsow and herlitter. Abanico Vet [Internet]. 2014;4(1):51-60. Available from: http://www.medigraphic.com/pdfs/abanico/av2014/av141f.pdf

11. Jensen, P. Comportamiento del cerdo. Etología de los animales domésticos. Zaragoza, España. Jensen (Editor), Editorial Acribia,2004. pp. 168-84.

12. Lahitte HB, Ferrari HR, Lázaro L. Sobre el etograma, 1: del etograma como lenguaje al lenguaje de los etogramas. Revista de Etología. 2002 Dec;4(2):129-41.

13. Lorenz K. The companion in the bird's world. The Auk. 1937. 54:24573

14. Nacipucha P.K.C. Bienestar del lechón en la fase de lactanción. Tesis doctoral. Facultad de veterinaria. Universidad de $\quad$ Murcia. 2014. 